Revista Eletrônica de Direito Processual - REDP.

Rio de Janeiro. Ano 11. Volume 18. Número 2. Maio a Agosto de 2017

Periódico Quadrimestral da Pós-Graduação Stricto Sensu em Direito Processual da UERJ

Patrono: José Carlos Barbosa Moreira. ISSN 1982-7636. pp. 53-71

www.redp.uerj.br

\title{
EL MENOSCABO DE LA DOBLE INSTANCIA EN EL JUICIO ORAL MERCANTIL TRASGREDE ESTÁNDARES DEL SIDH ${ }^{1}$
}

\section{THE IMPAIRMENT OF THE DOUBLE INSTANCE IN THE ORAL MERCANTIAL TRIAL TRASGRIES STANDARDS OF THE SIDH}

\begin{abstract}
Alfonso Jaime Martínez Lazcano
Abogado, Doctor en Derecho Público, profesor e Investigador de la Universidad Autónoma de Chiapas y profesor honorario de la Facultad de Derecho de la Universidad Nacional Autónoma de México (UNAM). Director de la Revista Jurídica Primera Instancia y Presidente del Colegio de Abogados Procesalistas Latinoamericanos. Miembro del Instituto Iberoamericano de Derecho Procesal. alfonso.martinez@unach.mx
\end{abstract}

RESUMEN: El trabajo presenta los parámetros de protección judicial y garantías procesales previstas en la Convención Americana de Derechos Humanos en cuanto la existencia de un recurso ordinario sencillo y eficaz, así como la naturaleza jurídica de la apelación diferente a la del juicio de amparo directo regulado en México; analiza la legislación vigente y los criterios emitidos por los tribunales nacionales respecto de la improcedencia de los recursos ordinarios en los juicios orales mercantiles determinando que tal situación no garantiza la justicia rápida y sí la arbitrariedad judicial.

PALABRAS CLAVE: Derechos humanos, Convención Americana, recursos ordinarios, apelación.

ABSTRACT: The paper presents the parameters of judicial protection and procedural safeguards provided for in the American Convention on Human Rights insofar as the

\footnotetext{
${ }^{1}$ Artigo recebido em 10/07/2017, sob dispensa de revisão.
} 
Revista Eletrônica de Direito Processual - REDP.

Rio de Janeiro. Ano 11. Volume 18. Número 2. Maio a Agosto de 2017

Periódico Quadrimestral da Pós-Graduação Stricto Sensu em Direito Processual da UERJ

Patrono: José Carlos Barbosa Moreira. ISSN 1982-7636. pp. 53-71

www.redp.uerj.br

existence of a simple and effective ordinary remedy, as well as the legal nature of the appeal different from that of the direct amparo trial regulated in Mexico ; Analyzes the current legislation and the criteria issued by the national courts regarding the inadmissibility of ordinary remedies in commercial oral trials determining that such a situation does not guarantee prompt justice and judicial arbitrariness.

KEYWORDS: Human rights, American Convention, ordinary appeals, appeal.

SUMARIO: I. Introducción. II. Recursos ordinarios. III. Clases de juicios orales mercantil. IV. Constitucionalidad de la falta de doble instancia en los juicios orales. V. Conclusiones. VI. Bibliohemerografía.

\section{INTRODUCCIÓN}

La creación del Sistema Interamericano de Protección de Derechos Humanos (SIDH) es consecuencia del desarrollo de muchas ideas de todo el mundo, esencialmente de Europa, con la finalidad de contraponerse a los excesos de los que ejercen el poder a nivel nacional sobre sus habitantes y promover políticas de inclusión a todos los seres humanos sin distinción, así impulsar los beneficios del desarrollo a la comunidad.

\section{El control de convencionalidad}

El control difuso de convencionalidad es una reciente forma de interpretar y aplicar el derecho, se generado a partir de la adopción de normas convencionales por las naciones, pero además se ha desarrollado a través de la jurisprudencia de esas disposiciones comunes por los organismos de supervisión convencionales, trasformado de forma radical el cómo deben actuar los operadores jurídicos para proteger los derechos humanos.

El control difuso de convencionalidad pretende evolucionar a los órganos jurisdiccionales de los Estados Parte del SIDH, de entes de competencia limitada a la aplicación de la ley a garantes de las disposiciones de carácter interamericanas y amplía el conjunto las fuentes y de criterios jurídicos con las que cuentan ahora los tribunales para resolver controversias, es síntesis, es un cambio copernicano. 
Revista Eletrônica de Direito Processual - REDP.

Rio de Janeiro. Ano 11. Volume 18. Número 2. Maio a Agosto de 2017

Periódico Quadrimestral da Pós-Graduação Stricto Sensu em Direito Processual da UERJ

Patrono: José Carlos Barbosa Moreira. ISSN 1982-7636. pp. 53-71

www.redp.uerj.br

2. Convención Americana sobre Derechos Humanos

Es el documento fundamental del SIDH llamado también Pacto de San José de Costa Rica, por haberse suscrito en ese país el 22 de noviembre de 1969, vigente a partir del 18 de julio de 1978. México es Estado Parte en la Convención Americana sobre Derechos Humanos (en lo sucesivo CADH) desde el 24 de marzo de 1981.

La CADH en el artículo $2^{\circ}$ ordena el:

Deber de Adoptar Disposiciones de Derecho Interno. Si el ejercicio de los derechos y libertades mencionados en el artículo 1 [de la CADH] no estuviere ya garantizado por disposiciones legislativas o de otro carácter, los Estados Partes se comprometen a adoptar, con arreglo a sus procedimientos constitucionales y a las disposiciones de esta $\mathrm{CADH}$, las medidas legislativas o de otro carácter que fueren necesarias para hacer efectivos tales derechos y libertades".

3. Corte Interamericana de Derechos Humanos

Es el órgano colegiado convencional de carácter jurisdiccional y consejero del SIDH.

La Corte Interamericana de Derechos Humanos (en lo posterior Corte IDH) quedó integrada el 22 de mayo de 1979, al termino de tres décadas de esfuerzos y proyectos, la Asamblea General de la Organización de los Estados Americanos eligió, durante su Séptimo Período Extraordinario de Sesiones, a los primeros jueces que la compondrían: tres centroamericanos, dos suramericanos, un caribeño y un estadounidense. ${ }^{2}$

México reconoció la competencia contenciosa de la Corte IDH el 16 de diciembre de 1998 y ha sido condenado en siete ocasiones por ésta en los siguientes procesos: Casos: Jorge Castañeda Gutman (2008); González y otras (“Campo Algodonero” 2009); Rosendo Radilla Pacheco (2009); Fernández Ortega (2010); Rosendo Cantú y Otra (2010); Cabrera García y Montiel Flores (2010), y García Cruz y Sánchez Silvestre (2013).

\subsection{Jurisprudencia de la Corte IDH}

\footnotetext{
2 García Ramírez, Sergio. La Corte Interamericana de Derechos Humanos, Porrúa, México, 2011, p. 107.
} 
Cada vez que la Corte IDH resuelve un caso contencioso ${ }^{3}$ emite diversos criterios jurisdiccionales de interpretación principalmente de la $\mathrm{CADH}$ que son vinculante para todos los Estados Parte del SIDH, así lo ha determinado la Suprema Corte de Justicia de la Nación (en lo posterior SCJN) en Pleno.

\section{Derechos Humanos}

Toda disposición o acto de protección jurídica que represente límites a los poderosos frente a los que no los son, así como el requerimiento de crear las condiciones necesarias para obtener lo mínimo indispensable de subsistencia, especialmente a los menos favorecidos por su condición socioeconómica, son en esencia el germen de lo que hoy conocemos como derechos humanos.

Instaurar las condiciones jurídicas para combatir la intolerancia ideología, las arbitrariedades, combatir la pobreza, la esclavitud, el acceso a la justicia real, a la educación, a la protección de la salud, a la vivienda digna, a vivir en un entorno natural adecuado para el desarrollo de la vida, el acceso al trabajo remunerado que permita adquirir los satisfactores básicos, entre otras.

De acuerdo con Mariscal Ureta los derechos humanos: "representan...aquellas prerrogativas inherentes a la naturaleza humana de la persona, indispensables para su desarrollo integral, individual y colectivo". ${ }^{4}$

\section{Acceso a la justicia}

El acceso a la justicia es el derecho humano básico que implica la posibilidad de protección de la tutela judicial, para resolver un conflicto de trascendía jurídica, mediante el cumplimiento de una serie de requisitos esenciales, como lo es la existencia de tribunales previamente establecidos a los hechos a juzgar, la imparcialidad, independencia judicial, el resolver en el plazo razonable, el derecho a la impugnación, entre otros.

\footnotetext{
3 También la Corte IDH emite jurisprudencia cuando dicta medidas provisionales y sentencias de cumplimiento de supervisión.

${ }^{4}$ Mariscal Ureta, Karla Elizabeth, Medio ambiente sano, derecho colectivo global, Porrúa, México, 2015, p. 10.
} 


\section{RECURSOS ORDINARIOS}

Los recursos ordinarios son medios de impugnación de las resoluciones judiciales previstos en la ley que regula específicamente el proceso, en este caso el Código de Comercio, al que tienen derecho las partes, con la finalidad de que se estudie nuevamente el proveído fuente del disenso por otro órgano jurisdiccional o por el mismo tribunal que lo dictó, y se tenga la posibilidad real, en un plazo razonable de que sea revocado, modificado o anulado por ser contrario a derecho.

El hecho que se establezcan recursos ordinarios contra las resoluciones intermedias y contra la sentencia implica cumplir con el derecho humano vinculado al debido proceso y fortalece el sistema de justicia.

Los recursos transmiten la noción que el sistema no tiene flancos débiles asintiendo que dentro de su misma funcionalidad y estructuración puedan ser revisados los fallos de los magistrados de rango inferior. Se refuerza de esta manera el grado de certeza de las decisiones judiciales brindando una mayor seguridad jurídica. ${ }^{5}$

L a CADH en el artículo 25, fracción I referente a la Protección Judicial prevé:

Toda persona tiene derecho a un recurso sencillo y rápido o a cualquier otro recurso efectivo ante los jueces o tribunales competentes, que la ampare contra actos que violen sus derechos fundamentales reconocidos por la Constitución, la ley o la presente Convención, aun cuando tal violación sea cometida por personas que actúen en ejercicio de sus funciones oficiales.

\section{Características}

Frente al yerro judicial de la autoridad, que en esencia representa una arbitrariedad, es fundamental contar como derecho procesal el tener al alcance un recurso ordinario para la corrección, el cual en forma general debe reunir las características de ser sencillo, sustanciado rápido y eficaz.

¿Qué significa que el recurso sea sencillo? ${ }^{5}$ Villalba Bernié, Pablo Darío, Reflexiones sobre el Sistema Interamericano de Derechos Humanos: una
visión crítica, revista jurídica Primera Instancia, número 5, 2015. 
Revista Eletrônica de Direito Processual - REDP.

Rio de Janeiro. Ano 11. Volume 18. Número 2. Maio a Agosto de 2017

Periódico Quadrimestral da Pós-Graduação Stricto Sensu em Direito Processual da UERJ

Patrono: José Carlos Barbosa Moreira. ISSN 1982-7636. pp. 53-71

www.redp.uerj.br

De acuerdo con el Diccionario de la Real Academia de la Lengua Española, entre diversas acepciones la palabra sencillo significa: "que no ofrece dificultad".

[...] el Tribunal [Corte IDH] ha sostenido que el artículo 8.2 (h) de la CADH se refiere a un recurso ordinario accesible y eficaz, es decir que no debe requerir mayores complejidades que tornen ilusorio este derecho. En ese sentido, las formalidades requeridas para que el recurso sea admitido deben ser mínimas y no deben constituir un obstáculo para que el recurso cumpla con su fin de examinar y resolver los agravios sustentados por el recurrente, es decir que debe procurar resultados o respuestas al fin para el cual fue concebido. ${ }^{6}$

\section{¿Qué significa que el recurso sea eficaz?}

Que el recurso sea eficaz quiere decir que a través de éste se pueda lograr la finalidad, cumplir con el objetivo o propósito para la cual se reglamentó: evitar el error judicial, mejorar la administración de justicia y depurar el proceso ante cualquier falla a través de un nuevo estudio del caso.

[...] Debe entenderse que, independientemente del régimen o sistema recursivo que adopten los Estados Partes y de la denominación que den al medio de impugnación de la sentencia condenatoria, para que éste sea eficaz debe constituir un medio adecuado para procurar la corrección de una condena errónea $[\ldots]^{7}$

La Corte IDH ha establecido que la existencia del recurso ordinario se relaciona con el derecho a la defensa:

a) Recurso ordinario: el derecho de interponer un recurso contra el fallo debe ser garantizado antes de que la sentencia adquiera la calidad de cosa juzgada, pues busca proteger el derecho de defensa evitando que quede firme una decisión adoptada en un procedimiento viciado y que contenga errores que ocasionarán un perjuicio indebido a los intereses de una persona. $^{8}$

\section{Código de Comercio}

El Código de Comercio regula los recursos ordinarios: revocación, reposición y apelación.

\footnotetext{
${ }^{6}$ Corte IDH. Caso Liakat Ali Alibux Vs. Surinam. Excepciones Preliminares, Fondo, Reparaciones y Costas. Sentencia de 30 de enero de 2014. Serie C No. 276, Párrafo 86.

7 Ídem.

${ }^{8}$ Cfr. Caso Herrera Ulloa Vs. Costa Rica, párr. 158, y Caso Liakat Ali Alibux Vs. Suriname, párr. 85.
} 


\subsection{Apelación 9}

El recurso ordinario de apelación es el medio idóneo por el cual las partes están en posibilidad de cuestionar la sentencia de fondo e interlocutoria y algunos autos intraprocesales expresando los agravios en los que se incurren, antes de que causen ejecutoria o sean firmes e inmutables, de carácter vertical al ser resuelto por un órgano jurisdiccional colegiado diferente al que dictó el proveído impugnado.

El término apelación proviene del latín appellare, que significa pedir auxilio. Es el medio impugnativo ordinario a través del cual una de las partes o ambas (apelante) solicita que un tribunal de segundo grado (ad quem) examine una resolución dictad dentro del proceso (materia judicandi) por el juez que conoce de la primera instancia. (a quo), expresando sus inconformidades al momento de interponerlo (agravios), con la finalidad de que el superior jerárquico, una vez que las analice y sin que pude suplir sus deficiencias (en estricto derecho), corrija sus defectos (errores in procedendo) modificándola o revocándola ${ }^{10}$.

\subsection{Agravios}

Un requisito esencial al interponer el recurso de apelación es la expresión de agravios, la parte recurrente debe decir por qué la resolución judicial viola el derecho, sea de fuente legal, constitucional o convencional, qué norma o principio se dejó de aplicar o no se aplicó, cabe señalar que esta será la materia de la revisión, a menos cuando existe suplencia de la queja o un control difuso de constitucionalidad o convencionalidad que debe ejercerse de oficio, en estos supuestos el examen se extiende más allá de lo planteado por las partes.

Esto significa que en la terminología de los tribunales se emplea la palabra agravio fundamentalmente en dos sentidos: 1) como argumento o razonamiento jurídico que tiende a demostrar el tribunal ad quem que el inferior violo determinados preceptos jurídicos al pronunciar una resolución, y 2) como la lesión o el perjuicio que se causa a una persona en sus derechos con la resolución impugnada. En el primer sentido se

\footnotetext{
${ }^{9}$ El Código de Comercio regula dos tipos de apelaciones: las inmediatas y las preventivas, la diferencia esencial es que las primeras se resuelven en forma independiente de la sentencia de fondo y las segundas simultáneamente cuando se apela la sentencia de fondo.

${ }^{10}$ Contreras Vaca, Francisco José, Derecho procesal civil, Oxford University Press, Vol. 2, México, 1999, pp. $45-46$.
} 
Revista Eletrônica de Direito Processual - REDP.

Rio de Janeiro. Ano 11. Volume 18. Número 2. Maio a Agosto de 2017

Periódico Quadrimestral da Pós-Graduação Stricto Sensu em Direito Processual da UERJ

Patrono: José Carlos Barbosa Moreira. ISSN 1982-7636. pp. 53-71

www.redp.uerj.br

habla, por ejemplo, de que los agravios son fundados; y en el segundo se dice que tal o cual resolución causan o no agravio a alguna persona. ${ }^{11}$

\subsection{Segunda instancia}

Por medio del recurso de apelación se accede a la segunda instancia, que implica un nuevo juicio, toda vez que la sentencia que se emita va sustituir al proveído impugnado, aun en el supuesto de que éste sea confirmado por el tribunal de alzada.

[...]..La impugnación se convierte en un verdadero proceso pues mediante la impugnación el proceso principal no es simplemente continuado sino que desaparece para dejar su puesto a otro proceso distinto, aunque ligado al anterior. ${ }^{12}$

Así al tribunal de segunda instancia se le devuelve la jurisdicción y actúa de pleno derecho; su fallo se integrará al expediente de primera instancia para su ejecución en reemplazo de refutado al no existir el reenvió.

La apelación es el instrumento normal de impugnación de las sentencias definitivas; en virtud de ella, se inicia la segunda instancia, el segundo grado del conocimiento del litigo sometido a proceso..., también en el derecho medieval español al recurso de apelación se le denomino recurso de alzada, ya que se interponía ante el tribunal superior, el tribunal de "alzada". Actualmente la apelación continúa siendo un recurso vertical. ${ }^{13}$

\section{4. Órgano colegiado}

El recurso ordinario de apelación permite que se reestudie la resolución y cuando se combate la sentencia de fondo dictada por un juez de primera instancia, le corresponde a un tribunal superior, constituido de forma colegiada, por integrantes mejor preparados y de mayor experiencia llevar acabo la revisión.

El refrán popular precisa que dos cabezas piensan mejor que una, en este caso los tribunales de segunda instancia están integrados por tres magistrados, sin embargo en contrapartida el trabajo en equipo requiere de un verdadero compromiso de grupo, lo cual es difícil de lograr si no hay responsabilidad mutua de los integrantes de foro judicial, de esta manera en forma brillante Carnelutti nos plantea las dos disyuntivas:

\footnotetext{
${ }^{11}$ Ovalle Favela, José, Derecho procesal civil, Oxford University Press, México, 1999, p. 242.

${ }^{12}$ Becerra Bautista, José, El proceso civil en México, Porrúa, México, 1999. p. 589.

${ }^{13}$ Ovalle Favela, op. cit., p. p. 239.
} 
Revista Eletrônica de Direito Processual - REDP.

Rio de Janeiro. Ano 11. Volume 18. Número 2. Maio a Agosto de 2017

Periódico Quadrimestral da Pós-Graduação Stricto Sensu em Direito Processual da UERJ

Patrono: José Carlos Barbosa Moreira. ISSN 1982-7636. pp. 53-71

www.redp.uerj.br

La constitución colegial del juez explica por la limitación de la mente humana por un lado, y por su diversidad por el otro: poniendo varios hombres juntos se consigue, se espera conseguir por lo menos, la construcción de una especie de superhombre, que debiera poseer mayores aptitudes para el juicio de las que posee en singular cada uno de los que lo integran: el fenómeno es el mismo que aquel por el cual se uncen el arado una o más yuntas de bueyes en vez de un solo buey; pero cualquiera se hace cargo de que el mayor rendimiento de la yunta está condicionado por el trabajo efectivo de cada uno de sus miembros, y no es fácil, por exigencias técnicas además de por razones psicológicas, obtener de todos los miembros del colegio judicial una participación igual en el trabajo común. ${ }^{14}$

\section{CLASES DE JUICIOS ORALES MERCANTIL}

Es factible de acuerdo a la legislación actual ${ }^{15}$ dividen en dos tipos de juicios orales en materia mercantil:

A) juicio oral mercantil es sentido ordinario, y

B) juicio ejecutivo mercantil oral.

A) juicio oral mercantil es sentido ordinario

Mediante reforma al Código de Comercio publicada en el Diario Oficial de la Federación, se adicionó el Título Especial Juicio Oral Mercantil el 27 de enero de 2011 y entró en vigor el 28 de enero de 2012, creándose como vía para resolver controversias mercantiles el juicio oral, para la tramitación de todas las contiendas sin limitación de cuantía, además se dispuso que contra las resoluciones pronunciadas en este tipo de procesos expresamente "no procederá recurso ordinario alguno".

a) cuantía

Además del territorio, la materia, el grado, la cuantía, que se refiere al valor económico del julio, determinan la competencia del órgano jurisdiccional, es decir, qué tribunal debe conocer el proceso, en ese punto, la cuantía en todos los casos se determinará

\footnotetext{
${ }^{14}$ Carnelutti, Francesco, Cómo se hace un proceso, Colofón SA, México, 202., p. 36.

${ }^{15}$ El Código de Comercio regula a los juicios mercantiles: a) ordinarios, b) orales, c) ejecutivos, y d) especiales, que son aquellos que se encuentren previstos por cualquier ley de índole comercial.
} 
Revista Eletrônica de Direito Processual - REDP.

Rio de Janeiro. Ano 11. Volume 18. Número 2. Maio a Agosto de 2017

Periódico Quadrimestral da Pós-Graduação Stricto Sensu em Direito Processual da UERJ

Patrono: José Carlos Barbosa Moreira. ISSN 1982-7636. pp. 53-71

www.redp.uerj.br

por concepto de suerte principal, sin tomar en consideración intereses y demás accesorios reclamados a la fecha de presentación de la demanda.

[...] el término cuantía del negocio, necesariamente implica el valor de la materia litigiosa, es decir, lo disputado en un juicio, determinado por las prestaciones reclamadas en cantidad líquida en la demanda inicial o susceptibles de cuantificarse mediante una operación aritmética sencilla, conforme a lo establecido por la Primera Sala de la SCJN en la jurisprudencia[...]. ${ }^{16}$

El juicio oral mercantil se tramitará sin limitación de cuantía, siempre y cuando el monto sea inferior a \$593,712.73 (Quinientos noventa y tres mil setecientos doce pesos 73/100 M.N.) ${ }^{17}$, por concepto de suerte principal y contra las resoluciones pronunciadas no procederá recurso ordinario alguno.

B) juicio ejecutivo mercantil oral

Mediante Decreto publicado en el Diario Oficial de la Federación el 25 de enero de 2017, también se adicionó el Título Especial Bis, Del Juicio Ejecutivo Mercantil Oral. Se tramitan por esta vía cuando la demanda se funda en uno de los documentos que traigan aparejada ejecución previstos en el artículo 1391 del Código de Comercio.

a) Vigencia sucesiva

El juicio ejecutivo mercantil oral entrará en vigor de forma sucesiva:

a) al año después de su publicación (25/enero/2018);

b) a partir del año siguiente al de la entrada en vigor se tramitarán todas las contiendas mercantiles cuyo monto sea menor a $\$ 1,000,000.00$;

c) a partir del segundo año siguiente al de la entrada en vigor se tramitarán todas las contiendas mercantiles cuyo monto sea menor a $\$ 1,500,000.00$, y;

d) a partir del tercer año siguiente al de la entrada en vigor se tramitarán todas las contiendas mercantiles sin limitación de cuantía.

\footnotetext{
${ }^{16}$ Gaceta del Semanario Judicial de la Federación, Libro 18, Tesis: III.5o.C.26 C (10a.), Registro: 2009151, mayo de 2015, Tomo III, Tesis: III.5o.C.26 C (10a.), p. 2263.

${ }^{17}$ Esta cantidad es actualizada por la Secretaria de Economía anualmente y debe ser publicada en el Diario Oficial de la Federación, a más tardar el 30 de diciembre de cada año.
} 


\section{C) Omisiones o irregularidades}

En ambas vías, oral mercantil y ejecutivo mercantil oral cuando existan misiones o irregularidades procesales procedimentales o Aclaración o adición al fallo se procederá:

a) Omisiones o irregularidades procesales procedimentales

Únicamente las partes podrán solicitar al juez, de manera verbal en la audiencia correspondiente, que subsane las omisiones o irregularidades que se llegasen a presentar en la substanciación, para el sólo efecto de regularizar el procedimiento. Asimismo, el juez podrá ordenar que se subsane toda omisión que notare en la substanciación, para el sólo efecto de regularizar el procedimiento.

b) aclaración o adición al fallo

Si las partes estimaren que la sentencia definitiva contiene omisiones, cláusulas o palabras contradictorias, ambiguas u oscuras, las partes podrán solicitar de manera verbal dentro de la audiencia en que se dicte, la aclaración o adición a la resolución, sin que con ello se pueda variar la substancia de la resolución, reiterando que "contra tal determinación no procederá recurso ordinario alguno".

D) ¿Qué significa que los juicios sean orales?

Que las personas que intervienen el proceso, las partes, testigos, peritos, se comuniquen a través del lenguaje hablado con el órgano jurisdiccional, además que este dialogo sea público, es decir, todas las actuaciones ordenadas por el tribunal durante la sustanciación, sin embargo la fase postulatoria conserva la forma escrita.

La mayor parte de la doctrina está de acuerdo en que este cambio requiere de una mejor preparación de los abogados, ante el temor de la evidencia de falta de pericia, pero lo fundamental es una mejor impartición de justicia, que eso está por verse. 
Revista Eletrônica de Direito Processual - REDP.

Rio de Janeiro. Ano 11. Volume 18. Número 2. Maio a Agosto de 2017

Periódico Quadrimestral da Pós-Graduação Stricto Sensu em Direito Processual da UERJ

Patrono: José Carlos Barbosa Moreira. ISSN 1982-7636. pp. 53-71

www.redp.uerj.br

La tarea del abogado exige considerablemente más esfuerzo... las herramientas... son las palabras, la voz, los gestos, el contacto visual y la misma presencia. ${ }^{18}$

Es indudable que las partes podrán constatar la eficacia de las participaciones del abogado contratado, al ser testigos de su desempeño en el tribunal.

[...] ya no podrán ocultar su ignorancia o negligencia de las leyes, pues deberán estar debidamente preparados, ya que su inconsistencia será visible en esta clase de procedimientos, en el que el interesado notará su deficiencia y con ello su no preparación para defender la causa que se le encomendó. Sus clientes finalmente descubrirán si se les prometió algún éxito en lo litigado. ${ }^{19}$

La afirmación anterior de Rodríguez Sánchez implica que antes de los juicios orales la ignorancia de los abogados era posible ocultarla, al ser genérica no es totalmente cierta, porque el éxito de los abogados no sólo requiere de la preparación o conocimiento de las leyes, sino que es una tarea compleja, al intervenir diversas personas o circunstancias en conflicto durante todo juicio, pero es válida en parte porque al ser más trasparente el juicio se puede constatar por los sentidos en forma directa el desempeño de los abogados y del personal judicial.

Para Rodríguez Sánchez la oralidad permite que los contendientes en cualquier momento, ante la constante presencia de éstas en las diligencias, puedan solucionar el litigio de manera auto-compositiva:

La oralidad tiene la ventaja de que pone a las partes frente a frente para que hablen ante el Juzgador, el juez observa y escucha con análisis crítico sus intervenciones, sobre todo en la fase de mediación o conciliación que se puede dar entre las mismas, lo que daría como resultado un acuerdo entre ellas. ${ }^{20}$

\section{D) Principios}

De acuerdo con el artículo 1390 bis 2 del Código de Comercio:

En el juicio oral mercantil se observarán especialmente los principios de oralidad, publicidad, igualdad, inmediación, contradicción, continuidad y concentración.

\footnotetext{
${ }^{18}$ De la Rosa Rodríguez, Paola Iliana, Éxito en el juicio oral, Porrúa, México, 2016, p. 1.

${ }^{19}$ Rodríguez Sánchez, Joaquín, Juicio oral mercantil, Editorial Flores, México, 2015, p. 5.

20 Ídem.
} 
Revista Eletrônica de Direito Processual - REDP.

Rio de Janeiro. Ano 11. Volume 18. Número 2. Maio a Agosto de 2017

Periódico Quadrimestral da Pós-Graduação Stricto Sensu em Direito Processual da UERJ

Patrono: José Carlos Barbosa Moreira. ISSN 1982-7636. pp. 53-71

www.redp.uerj.br

Dos principios destacan en los llamados juicios orales que debemos resaltar y destacar: uno, el acceso real y efectivo a la justicia; y dos, el principio de publicidad. ${ }^{21}$

La idea de principio implica inició, así también lo principal, de acuerdo con el Diccionario de la Real Academia de la Lengua Española, entre diversas acepciones de esta palabra se encuentra: "Primer instante del ser de algo", "Norma o idea fundamental que rige el pensamiento o la conducta".

Principio es entre sus significados, el inicio o la causa; a la base fundamental de una ideología; lo que da razón a un pensamiento.

El término principio (del latín principium) tiene entre sus significados los de base, los de origen, razón fundamental sobre la cual se procede discurriendo en cualquier materia; normas o ideas fundamentales que rige el pensamiento o la conducta. ${ }^{22}$

a) Reglas y principios

Existe una diferencia operativa entre los principios y las reglas (normas en sentido tradicional o estricto). Los principios no están diseñados a través de una hipótesis normativa que establezca sus límites, no son creados para regular una situación específica como las reglas, no se aplican a través de una consecuencia previamente definida, sino que son criterios orientadores para ser utilizados en la resolución de un conflicto de acuerdo con las características y el contexto de éste, al entorno físico o de situación, ya sea político, histórico, cultural o de cualquier otra índole. ${ }^{23}$

Los principios no son, como las reglas, comandos inmediatamente descriptivos de conductas específicas, sino normas que consagran determinados valores o indican fines públicos que se deben realizar a través de distintos medios. La definición del contenido de cláusulas como la dignidad de la persona humana, racionalidad, solidaridad o eficiencia, también trasfieren al para el intérprete una dosis de discrecionalidad. ${ }^{24}$

\footnotetext{
${ }^{21}$ Witker V., Jorge, Juicios Orales y derechos humanos, IIJ-UNAM, México, 2016, introducción.

${ }^{22}$ Ruiz Torres, Humberto Enrique, Diccionario del juicio de amparo, editorial Oxford, México 2005, p 296.

23 Lazcano, Alfonso Jaime Martínez. Princípios jurídicos de la Convención Americana de Derechos Humanos y su aplicación en los casos mexicanos. Revista Direitos Emergentes na Sociedade Global, [S.1.], v. 4 n. 2, p. 43-76, ago. 2016. ISSN 2316-3054. Disponível em: <https://periodicos.ufsm.br/REDESG/article/view/21239>. Acesso em: $08 \quad$ maYO 2017. doi:http://dx.doi.org/10.5902/2316305421239.

${ }^{24}$ Barroso, Luis Roberto, El neoconstitucionalismo y la constitucionalización del derecho, IIJ UNAM, 2008, p.14.
} 


\section{CONSTITUCIONALIDAD DE LA FALTA DE DOBLE INSTANCIA EN LOS JUICIOS ORALES}

No obstante la Primera Sala de la SCJN opina que no es necesaria la segunda instancia y precisa que el juicio de amparo es un medio de impunidad extraordinario que cumple con el fin de revisar la sentencias de los juicios orales mercantiles, prácticamente como segunda instancia.

A continuación se reproduce el criterio SCJN cuyo rubro es: Juicio oral mercantil. El artículo 1390 bis del Código de Comercio que no prevé el derecho a una segunda instancia, es constitucional, y se analizan sus argumentos:

El precepto citado prevé que se tramitarán en el juicio oral mercantil todas las contiendas cuya suerte principal sea inferior a la que establece el artículo 1339 del Código de Comercio para que un juicio sea apelable, sin que sean de tomarse en consideración intereses y demás accesorios reclamados a la fecha de interposición de la demanda, y que contra las resoluciones pronunciadas en dicho juicio no procederá recurso ordinario alguno. ${ }^{25}$

Se ratifica la negación del legislador de establecer un sistema de impugnación ordinario, ni el recurso de revocación, reposición ni apelación basados exclusivamente del valor económico de lo reclamado.

Para tener una idea de la cuantía establecida por el legislador para el juicio oral mercantil en comparación al salario mínimo actual (\$80.04 pesos diarios), dicho monto representa más de 20 años de trabajo, lo que parece en obviedad que las clases sociales más vulnerables son las que tendrán una instancia menos de acceso a la justicia, y me refiero especialmente a cuando éstas tengan la calidad de demandado, lo que parece que la justicia "pronta" tiene un sello discriminatorio.

El artículo $1^{\circ}$, último párrafo de la Constitución establece:

Queda prohibida toda discriminación motivada por... la condición social...o cualquier otra que atente contra la dignidad humana y tenga por objeto anular o menoscabar los derechos y libertades de las personas".

\footnotetext{
${ }^{25}$ Gaceta del Semanario Judicial de la Federación, Tesis: 1a. LX/2016 (10a.), Registro: 2011234, Libro 28, marzo de 2016, Tomo I, p. 986.
} 
Revista Eletrônica de Direito Processual - REDP.

Rio de Janeiro. Ano 11. Volume 18. Número 2. Maio a Agosto de 2017

Periódico Quadrimestral da Pós-Graduação Stricto Sensu em Direito Processual da UERJ

Patrono: José Carlos Barbosa Moreira. ISSN 1982-7636. pp. 53-71

www.redp.uerj.br

Es innegable que el artículo 1339 del Código de Comercio menoscaba el derecho de impugnación por las condiciones económicas. Ahora bien, el artículo 1390 Bis citado, al limitar el derecho a una segunda instancia es constitucional, pues el legislador, al determinar que el juicio oral mercantil es uniinstancial, no excluye el derecho a la doble instancia de forma generalizada, sino que lo hace excepcionalmente, ya que dicha exclusión sólo es aplicable a los juicios orales mercantiles. ${ }^{26}$

El hecho que la ley de forma general límite el derecho a impugnar es más grave que lo haga de manera particular, no puede ser constitucional y menos de convencional tal impedimento, en la práctica tendremos inicialmente dos tipos de justicia dependiendo las condiciones económicas de los contendientes en el proceso.

[...] además de que persigue una finalidad constitucionalmente legítima, pues tiene por objeto hacer el procedimiento mercantil más ágil y eficiente, lo que implica el respeto al principio de una administración de justicia pronta y expedita, contenido en el artículo 17 de la Constitución Política de los Estados Unidos Mexicanos, imprimiéndole celeridad al proceso judicial correspondiente, y encaminada a fomentar la economía procesal y la eficacia de la rama judicial. ${ }^{27}$

El artículo 17 constitucional si bien es cierto se refiere a las exigencias de la administración de justicia para todo tipo de proceso y no en particular del juicio oral mercantil, pero ello no implica por ningún motivo que por sí mismo el proceso sea "eficiente", como de manera brillante expone Carnelutti: “...la justicia si es segura no es rápida, y si es rápida no es segura...quien va despacio, va bien y va lejos..."28

Además, es una medida razonable, ya que responde a la mayor urgencia de obtener una decisión definitiva y evita los costos que implican juicios prolongados y complejos, ya que tener que agotar necesariamente varias instancias puede provocar demora y más gastos en perjuicio del patrimonio de las partes, lo cual generalmente no se justifica cuando el asunto es de poca cuantía. ${ }^{29}$

\footnotetext{
26 Ídem.

27 Ídem.

${ }^{28}$ Carnelutti, Francesco, op. cit., p.16.

${ }^{29}$ Op. cit. Registro: 2011234, Libro 28, marzo de 2016, Tomo I, p. 986.
} 
Todo juicio es un acto complejo en sí mismo, es indiscutible que de lo contrario no se requeriría de la intervención de los tribunales, la "urgencia" de obtener justicia puede anticiparse con medidas cautelares y no limitando derechos.

El acceso a la justicia mediante la acción se desenvuelve en una serie de actos relacionados entre sí, que no debe reducirse o eliminarse supeditados exclusivamente a la cuantía del negocio.

Asimismo, genera un criterio de selección para el control de legalidad por órganos jurisdiccionales superiores, para que éstos se concentren en resolver asuntos que se consideran más complejos. ${ }^{30}$

Este argumento es una falacia, la complejidad de los asuntos no está determinada por la cuantía del negocio, por el contrario en muchas ocasiones los de menor monto son más complejos porque las partes no tienen sal establecer la relación sustantiva los mismos recursos para garantizar las obligaciones.

De ahí que se trate de una medida proporcional, pues aun limitándose el derecho a la segunda instancia, no se priva al gobernado del acceso a la justicia ni se le deja en estado de indefensión, ya que en el procedimiento uniinstancial también deben respetarse las formalidades esenciales del proceso, y se tiene la posibilidad de impugnar dicha resolución mediante el juicio de amparo, de manera que, aun cuando no exista en la jurisdicción ordinaria un recurso disponible para impugnar las resoluciones adversas, existe un recurso extraordinario. ${ }^{31}$

El criterio confiesa que se limita la segunda instancia, y falsamente se dice que no se priva del acceso a la justicia, porque este derecho, como antes se explica, representa un conjunto de requisitos para la validez de un proceso, independientemente que se diga que se deben respetar "las formalidades esenciales del proceso", situación que debe hacerse en todo juicio, tal afirmación no es una garantía que se haga cuando se privan de derechos a las partes.

Si bien es cierto es factible impugnar la sentencia del juicio oral mercantil mediante el juicio de amparo directo, como en todo proceso judicial ${ }^{32}$, también lo es que es un

\footnotetext{
30 Ídem.

31 Ídem.

32 El juicio de amparo directo procede contra sentencias, laudos y resoluciones que pongan fin al procedimiento.
} 
recurso extraordinario, no ordinario, además, en cuanto el tiempo, en el amparo directo existe reenvió lo que deja abierta muchas situaciones desde exceso o defecto en el cumplimiento de la sentencia de amparo, inconformidad en la declaración de cumplimiento, entre otros supuestos más, aunado que el juicio de amparo no es un recurso sencillo y eficaz para reparar íntegramente violaciones a derechos humanos.

En conclusión se priva de la segunda instancia a las partes exclusivamente por cuestiones económicas.

Finalmente, la exclusión de que se trata obedece a criterios objetivos, pues el factor cuantía, como elemento para determinar la procedencia del juicio oral mercantil, constituye un quantum objetivo que no se fundamenta en los ingresos ni en la condición social de las personas, sino en el monto global de la pretensión. ${ }^{33}$

No es necesario decir que las contiendas en el cual las partes reclaman mayores montos se relacionan directamente con su estrato social, si es preciso sacrificar la calidad de la justicia por la rapidez, lo justo es que se haga de forma general y no mediante distinciones que atentan contra la dignidad.

Es de destacarse que en contra de la tesis analizada, sin que se conozcan las razones, contra la mayoría de la Primera Sala de la SCJN el Ministro José Ramón Cossío Díaz se reservó el derecho de formular voto particular.

\section{CONCLUSIONES:}

La intención principal de rapidez del desarrollo del procedimiento no está garantizada por la práctica judicial que impera en los tribunales con la improcedencia de los recursos ordinarios en los juicios orales mercantiles, lo que si genera, es la merma en la calidad de la administración de la justicia, además posibilita la generación de jueces con una actitud arbitraria, porque la regulación del procedimiento depende en la jurisdicción ordinaria nada más de éstos, que ante las audiencias públicas poco está garantizado el reconocimiento del error judicial, ya que su proceder sólo puede ser cuestionado a través de otra jurisdicción hasta que se emita la sentencia de fondo, lo que implica tiempo y un sistema complejo de impugnación, más en materia mercantil en la cual no se suple la

\footnotetext{
${ }^{33}$ Op. cit. Registro: 2011234, Libro 28, marzo de 2016, Tomo I, p. 986.
} 
Revista Eletrônica de Direito Processual - REDP.

Rio de Janeiro. Ano 11. Volume 18. Número 2. Maio a Agosto de 2017

Periódico Quadrimestral da Pós-Graduação Stricto Sensu em Direito Processual da UERJ

Patrono: José Carlos Barbosa Moreira. ISSN 1982-7636. pp. 53-71

www.redp.uerj.br

deficiencia de la queja por regla y que en los jueces no es habitual a ejercer el control difuso de convencionalidad.

El amparo directo se tramita ante los tribunales colegiados de circuito, quienes por la carga de trabajo y el menor interés que le asignan a los procesos mercantiles frente a violaciones más graves de derechos humanos, no responde la rapidez buscada por esta artificial segunda instancia. Aunado que el juicio de amparo es un proceso complicado, lento y el fallo, en caso de proteger al quejoso, provoca el reenvío y la posibilidad de inconformarse del cumplimiento.

Es importante destacar la mala experiencia en los procesos laborales por falta de segunda instancia natural y que en la realidad tampoco ha garantizado la justicia rápida la intervención de los tribunales colegiados de circuito como tribunales de alzada, pero si la pésima administración de justicia de las juntas de conciliación y arbitraje.

Es innegable que el artículo 1339 del Código de Comercio menoscaba el derecho de impugnación por las condiciones económicas y a un pleno acceso a la justicia.

\section{REFERÊNCIAS BIBLIOGRÁFICAS}

A) Doctrina:

BARROSO, Luis Roberto, El neoconstitucionalismo y la constitucionalización del derecho, IIJ UNAM, 2008.

BECERRA BAUTISTA, José, El proceso civil en México, Porrúa, México, 1999.

CARNELUTTI, FRANCESCO, Cómo se hace un proceso, Colofón SA, México, 2002.

CONTRERAS VACA, Francisco José, Derecho procesal civil, Oxford University Press, Vol. 2, México, 1999.

DE LA ROSA RODRÍGUEZ, PAOLA ILIANA, Éxito en el juicio oral, Porrúa, México, 2016.

GARCÍA RAMÍREZ, Sergio. La Corte Interamericana de Derechos Humanos, Porrúa, México, 2011. 
Revista Eletrônica de Direito Processual - REDP.

Rio de Janeiro. Ano 11. Volume 18. Número 2. Maio a Agosto de 2017

Periódico Quadrimestral da Pós-Graduação Stricto Sensu em Direito Processual da UERJ

Patrono: José Carlos Barbosa Moreira. ISSN 1982-7636. pp. 53-71

www.redp.uerj.br

LAZCANO, Alfonso Jaime Martínez. Princípios jurídicos de la Convención Americana de Derechos Humanos y su aplicación en los casos mexicanos. Revista Direitos Emergentes na Sociedade Global, [S.1.], v. 4, n. 2, p. 43-76, ago. 2016. ISSN 2316-3054. Disponível em: <https://periodicos.ufsm.br/REDESG/article/view/21239>. Acesso em: 08 mayo 2017. doi:http://dx.doi.org/10.5902/2316305421239.

MARISCAL URETA, Karla Elizabeth, Medio ambiente sano, derecho colectivo global, Porrúa, México, 2015.

OVALLE FAVELA, José, Derecho procesal civil, Oxford University Press, México, 1999. RODRÍGUEZ SÁNCHEZ, Joaquín, Juicio oral mercantil, Editorial Flores, México, 2015

RUIZ TORRES, Humberto Enrique, Diccionario del juicio de amparo, editorial Oxford, México 2005.

VILLALBA BERNIÉ, Pablo Darío, Reflexiones sobre el Sistema Interamericano de Derechos Humanos: una visión crítica, revista jurídica Primera Instancia, número 5, 2015.

WITKER V., Jorge, Juicios orales y derechos humanos, IIJ-UNAM, México, 2016.

B) Criterios jurisdiccionales

Corte IDH. Caso Liakat Ali Alibux Vs. Surinam.

Corte IDH. Caso Herrera Ulloa Vs. Costa Rica,

Corte IDH. Caso Liakat Ali Alibux Vs. Suriname.

Gaceta del Semanario Judicial de la Federación, Libro 18, Tesis: III.5o.C.26 C (10a.), Registro: 2009151, mayo de 2015, Tomo III, Tesis: III.5o.C.26 C (10a.).

Gaceta del Semanario Judicial de la Federación, Tesis: 1a. LX/2016 (10a.), Registro: 2011234, Libro 28, marzo de 2016, Tomo I. 